\title{
Plant and algal toxicity of persistent free radicals and reactive oxygen species generated by heating anthracene-contaminated soils from 100 to $600^{\circ} \mathrm{C}$
}

\author{
Jinbo Liu ${ }^{1} \cdot$ Ning Gao $^{1} \cdot$ Xin Wen ${ }^{1} \cdot$ Hanzhong Jia ${ }^{1} \mathbb{D} \cdot$ Eric Lichtfouse ${ }^{2} \mathbb{D}$
}

\begin{abstract}
Persistent free radicals (PFRs) are emerging contaminants of increasing concern, yet their formation, fate, toxicity and health risk are poorly known. Thermal treatment, a common remediation technique to clean industrial soils, induces the formation of PFRs, which could paradoxically increase soil toxicity, contrary to the original objective of remediation. Actually, there is little knowledge on the formation and toxicity of PFRs in soils contaminated by polycyclic aromatic hydrocarbons (PAHs). Here we studied the generation of PFRs of soils spiked with anthracene and heated $1 \mathrm{~h}$ from 100 to $600{ }^{\circ} \mathrm{C}$, using electron paramagnetic resonance. We also investigated the formation of reactive oxygen species (ROS), e.g. superoxide radical $\left(\mathrm{O}_{2}{ }^{-}\right)$, hydrogen peroxide $\left(\mathrm{H}_{2} \mathrm{O}_{2}\right)$ and hydroxyl radical $(\cdot \mathrm{OH})$, in the aqueous phase of thermal-treated soil, and the impact of heating on soil oxidative potential, wheat growth and green algae activity. Results showed that PFRs, ROS, soil oxidative potential, plant toxicity and algal toxicity show a similar trend with an increase from 100 to $300{ }^{\circ} \mathrm{C}$, followed by a decrease to $600{ }^{\circ} \mathrm{C}$. Scavenger trapping tests reveal that algal toxicity is mainly due to the generation of $\mathrm{O}_{2}{ }^{-}, \cdot \mathrm{OH}^{\circ}$ and $\mathrm{H}_{2} \mathrm{O}_{2}$ induced by anthracene-PFRs and that anthracene and anthracene-PFRs have negligible direct algal toxicity. Overall, our findings reveal the unintended formation of toxic compounds peaking at $300{ }^{\circ} \mathrm{C}$ during the thermal remediation of PAHcontaminated soils. These results should help to assess the environmental risk of thermally treated PAH-contaminated soils.
\end{abstract}

Keywords Thermal treatment · Polycyclic aromatic hydrocarbons $\cdot$ Persistent free radicals $\cdot$ Reactive oxygen species Oxidative potential $\cdot$ Wheat growth $\cdot$ Green algae

\section{Introduction}

Polycyclic aromatic hydrocarbons (PAHs) are a class of priority organic pollutants displaying teratogenicity, carcinogenicity and mutagenicity (Haritash and Kaushik 2009). About $90 \%$ of environmental PAHs end up into soils and

Supplementary Information The online version contains supplementary material available at (https://doi.org/10.1007/ s10311-021-01193-z).

Hanzhong Jia

jiahz@nwafu.edu.cn

1 Key Laboratory of Plant Nutrition and the Agri-environment in Northwest China, Ministry of Agriculture, College of Natural Resources and Environment, Northwest A \& F University, Yangling 712100, China

2 Aix-Marseille University, CNRS, IRD, INRAE, Coll France, CEREGE, 13100 Aix en Provence, France sediments, owing partly to their excellent hydrophobic property (Eriksson et al. 2000). PAHs may then be transferred to plants, animals, milk and blood (Grova et al. 2000; Laurent et al. 2001, 2002; Crépineau et al. 2003). The concentration of PAHs in contaminated soils ranges from $1 \mu \mathrm{g} \mathrm{kg}^{-1}$ to tens of thousands mg kg-1 (Bryselbout et al. 2000; Eriksson et al. 2000; Kanaly and Harayama 2000). The chemical stability of PAHs and soil conditions such as physical sequestration and anoxia inhibit the degradation of PAHs (Lichtfouse et al. 1997; Zhang et al. 2015). For instance, ancient gasworks soils contaminated by PAHs still display plant toxicity by 1-2 aromatic hydrocarbons several decades after gaswork closure (Henner et al. 1999). Therefore, rapid and effective methods are needed to remediate PAHs contaminated soil (Henner et al. 1997).

Remediation techniques of PAH-contaminated soils include chemical oxidation (Jia et al. 2011, 2018), soil washing (Pourfadakari et al. 2019), bioremediation (Haritash and Kaushik 2009) and thermal treatment (Peng et al. 
2018). Thermal treatment is widely applied due to its high removal efficiency, low cost and short time (Merino and Bucala 2007; Falciglia et al. 2011). The removal efficiency of the 16 priority PAHs increases with temperature, attaining $98.0 \%$ at $500{ }^{\circ} \mathrm{C}$ (Chen et al. 2020). Peng et al. (2018) found that phenanthrene was almost totally converted to $\mathrm{H}_{2}$, $\mathrm{CO}_{2}$, and $\mathrm{CH}_{4}$ within the first $15 \mathrm{~s}$ at $800{ }^{\circ} \mathrm{C}$. During thermal treatment, various mechanisms may explain the decrease in extractable PAHs, such as desorption (Peng et al. 2018), volatilization (Falciglia et al. 2011), degradation (Zhang et al. 2019) and formation of bound residues (Lichtfouse et al. 1998; Kronimus et al. 2006), the respective contribution of which being poorly known. Transformation, e.g. oxidation, has also been evidenced recently during the removal of benzo[a]pyrene-spiked soils at $100-200{ }^{\circ} \mathrm{C}$, despite desorption being considered as the main removal mechanism (Jia et al. 2020). We also found that the transformation of benzo[a]pyrene in heated soils induces the formation of persistent free radicals (PFRs) (Liu et al. 2020). Since thermal treatment is commonly applied to clean PAH-contaminated soils (Kuppusamy et al. 2016), this remediation technique may pose potential health risks due to the formation of PFRs. Yet knowledge on the formation and toxicity of PFRs in soils is limited.

Soil particles containing PFRs generate reactive oxygen species (ROS) such as singlet oxygen ${ }^{1} \mathrm{O}_{2}$, superoxide radical $\mathrm{O}_{2}{ }^{--}$, hydrogen peroxide $\mathrm{H}_{2} \mathrm{O}_{2}$ and hydroxyl radical . $\mathrm{OH}$, which are known to induce toxicity to living organisms by oxidative stress (Dellinger et al. 2001; Khachatryan et al. 2011, 2014; Jia et al. 2016; Zhu et al. 2019). Oxidative stress is usually caused by an imbalance of ROS in exposed cells or tissues (Paul et al. 2012). Oxidative stress can be measured by the oxidative potential, an indicator of ROSgenerating potential of particles that correlates well with adverse effects in acellular assays (Paul et al. 2012; Chen et al. 2018). Since toxicity mechanisms of soil PFRs are poorly known, we hypothesized that measuring the oxidative potential of thermally treated PAH-contaminated soils would give some insight on the possible role of ROS. Therefore, here we heated an anthracene-spiked soil at $100-600{ }^{\circ} \mathrm{C}$ during $1 \mathrm{~h}$ to study the formation of PFRs and ROS, and to measure the toxicity for algae and wheat, because algal tests are highly sensitive and wheat grows in a wide range of soil conditions (Banks and Schultz 2005; Inckot et al. 2011; Wang et al. 2016). We used compound-specific radical scavengers to distinguish the toxicity contribution of PFRs and ROS. The obtained results would shed light on the potential environmental risk of thermally treated PAH-contaminated soil and underneath mechanisms.

\section{Materials and methods}

\section{Chemicals}

High purity of 5,5-dimethyl-1-pyroline-N-oxide (DMPO, > 97\%), dithiothreitol (DTT, 99\%), 5,5-dithiobis2-nitrobenzoic acid (DTNB, 98\%), tert-butanol (TBA), anthracene (ANT, 98\%), methanol (chromatographic grade), dimethyl sulfoxide (DMSO, 99\%) and ascorbic acid (AA, > 99\%) were obtained from J\&K Scientific Ltd. (Beijing, China). Superoxide dismutase (SOD, $>2500 \mathrm{U} / \mathrm{mg}$ ) and catalase (CAT, $>2000 \mathrm{U} / \mathrm{mg}$ ) were purchased from Beijing Solarbio Science \& Technology Co., Ltd. Potassium phosphate monobasic-sodium hydroxide $\left(\mathrm{KH}_{2} \mathrm{PO}_{4}\right)$ and disodium hydrogen phosphate $\left(\mathrm{Na}_{2} \mathrm{HPO}_{4}\right)$ were guaranteed reagents, purchased from Kemiou Chemical Reagent Co., Tianjin. Dichloromethane and acetone were of analytical grade from Sinopharm Chemical Reagent Co., Shanghai.

\section{Preparation of soils contaminated by anthracene}

Coastal solonchaks were sampled from surface-layer soil $(0-20 \mathrm{~cm})$ in Tianjin province of China $\left(38^{\circ} 45^{\prime} \mathrm{N}, 117^{\circ}\right.$ $\left.06^{\prime} \mathrm{E}\right)$. Soil samples were air-dried for $24 \mathrm{~h}$ at about $23^{\circ} \mathrm{C}$ and then sieved through 100-mesh before analysis. Soil physicochemical properties including organic carbon (OC), clay and metal contents, $\mathrm{pH}$ and cation exchange capacity (CEC) were analyzed. Detailed analysis methods are provided in supplementary material Text S1. Soil pH (8.29), OC (12.77 $\left.\mathrm{g} \mathrm{kg}^{-1}\right)$, CEC (24.67), clay (6.37\%), silt (78.14\%), sand (15.49\%), Fe (21,084 mg kg-1), Mn (397 $\left.\mathrm{mg} \mathrm{kg}^{-1}\right)$, $\mathrm{Cu}\left(24 \mathrm{mg} \mathrm{kg}^{-1}\right)$ and $\mathrm{Zn}\left(17 \mathrm{mg} \mathrm{kg}^{-1}\right)$. Anthracene was below detection limits in original soils. The preparation of anthracene-contaminated soil was previously described (Liu et al. 2020). Briefly, $1 \mathrm{~g}$ of soil sample was mixed with $1 \mathrm{~mL}$ of acetone solution containing $1000 \mathrm{mg} \mathrm{L}^{-1}$ of anthracene. Anthracene-containing soil samples were placed in the dark at about $23{ }^{\circ} \mathrm{C}$ until the acetone was completely evaporated. The anthracene-contaminated soils were then stored at $-4{ }^{\circ} \mathrm{C}$ for subsequent experiments. The final concentration of anthracene in soil samples ranged from 983 to $1012 \mathrm{mg} \mathrm{kg}^{-1}$.

\section{Thermal treatment of anthracene-contaminated soils}

Thermal treatment was performed in a quartz boat heated by a pipe furnace under a continuous flow of $\mathrm{N}_{2}$ with a flow rate of $1 \mathrm{~L} / \mathrm{min}$. The thermocouple of the pipe furnace recorded the temperature and guaranteed that the required heating temperature was reached. Before the heating 
started, the air inside the pipe furnace was exhausted by flushing $\mathrm{N}_{2}$ for $10 \mathrm{~min}$. Then, $5 \mathrm{~g}$ of anthracene-contaminated soil was placed in a quartz boat, transferred into the pipe furnace, and then held there at a fixed temperature for $1 \mathrm{~h}$. After cooling down to about $23{ }^{\circ} \mathrm{C}$, the soil was stored in sealed polyethylene bags prior to analysis. A blank experiment with the original soil (without anthracene) was heated under the same conditions; this experiment did no show EPR signals (Figure S1). In addition, unheated anthracene-spiked soils were used as control (CT). Residual concentration of anthracene in soils after thermal treatments was quantified by high-performance liquid chromatography (HPLC-UV, Thermo Fisher Scientific U3000, USA). The specific extraction and determination methods are presented in Text S2.

The variations of soil properties, including soil $\mathrm{pH}$, water-holding capacity, organic carbon and dissolved organic carbon, before and after thermal treatment are presented in Text S3 and Table S1.

\section{Persistent free radicals and reactive oxygen species}

Thermally treated soils and control were extracted under various conditions to analyze persistent free radicals (PFRs) and reactive oxygen species (ROS) as described by Zhao et al. (2020) and Liu et al. (2020). PFRs and ROS were analyzed by an electron paramagnetic resonance (EPR) spectrometer (Bruker EMXmicro-6/1/P/L, Karlsruhe, Germany) at room temperature, about $23^{\circ} \mathrm{C}$. Specifically, $50 \mathrm{mg}$ of thermally treated soil was placed into a $1.5 \mathrm{~mL}$ centrifuge tube, and mixed with $300 \mu \mathrm{L}$ of acetone and dichloromethane $1 / 1 \mathrm{v} / \mathrm{v}$ to extract the PFRs effectively (Zhao et al. 2020). The mixture was vortexed by Vortex Genie for $1 \mathrm{~min}$ and filtrated through a $0.45 \mu \mathrm{m}$ nylon membrane. The filtrate was sucked with a capillary tube then loaded in the EPR tube for PFRs analysis.

For ROS, analysis of hydroxyl radical $\cdot \mathrm{OH}$ involved extraction of $50 \mathrm{mg}$ of soil by $300 \mu \mathrm{L}$ of $0.1 \mathrm{M} 5,5$-dimethyl-1-pyrroline $N$-oxide (DMPO) aqueous solution. Superoxide radical $\mathrm{O}_{2}{ }^{--}$involved extraction of $50 \mathrm{mg}$ of soil by $300 \mu \mathrm{L}$ of $0.1 \mathrm{M}$ DMPO/DMSO. Other steps were carried out under the same conditions as mentioned above. EPR parameters are provided in Text S4.

Determination of hydrogen peroxide $\mathrm{H}_{2} \mathrm{O}_{2}$ concentration involved preparing a $10 \mathrm{~g} / \mathrm{L}$ suspension of soils, filtering $5 \mathrm{~mL}$ of suspension and analysis using the hydrogen peroxide assay kit from Solarbio Life Sciences Co., Beijing. Control experiments were paralleled by measuring the signals in the $250 \mu \mathrm{L}$ of $1.0 \mathrm{mM}$ hydrogen peroxide standard and $250 \mu \mathrm{L}$ of ultrapure water. The concentration of $\mathrm{H}_{2} \mathrm{O}_{2}$ produced by thermal treated soil samples was calculated by comparing the absorbance with control experiments.

\section{Soil oxidative potential}

The oxidative potential of the soil samples was determined by an acellular in vitro assay, the dithiothreitol assay (Tong et al. 2018). The oxidative potential was calculated as massnormalized dithiothreitol and ascorbate decay rates. Specifically, $5.0 \mathrm{mg}$ of soil was dispersed in $9.8 \mathrm{~mL}$ of $0.05 \mathrm{M}$ potassium phosphate buffer made with $0.01 \mathrm{M} \mathrm{KH}_{2} \mathrm{PO}_{4}$ and $0.04 \mathrm{M} \mathrm{Na}_{2} \mathrm{HPO}_{4}$ (pH 7.4). After 5 min of incubation at $37^{\circ} \mathrm{C}, 200 \mu \mathrm{L}$ of $1.0 \mathrm{mM}$ dithiothreitol solution was added, and the mixture was incubated $10 \mathrm{~min}$ in a thermostatic bath set at $37{ }^{\circ} \mathrm{C}$ with constant shaking. Then, $400 \mu \mathrm{L}$ of the mixture was mixed with $20 \mu \mathrm{L}$ of $1.0 \mathrm{mM}$ DTNB solution and filtered. The absorbance of the filtrate was measured to determine the residual dithiothreitol concentration at $412 \mathrm{~nm}$ using an Evolution 201 UV-Visible spectrophotometer (Thermo Scientific, USA). Following the same procedures, blank and control experiments (without soils) were run in parallel. The depletion rate of dithiothreitol was calculated with a zero-order kinetic equation, and the control value subtracted.

\section{Soil toxicity to plant germination and growth}

To investigate the possible reuse of the thermally treated PAHs soil, wheat vegetation germination and growth experiments were conducted. Wheat seed germination was determined by placing 30 seeds in layers of moistened soil within a glass petri dish. The germination dishes were placed in a growth chamber at $25{ }^{\circ} \mathrm{C}$ under dark conditions until the seed germination percentage was constant. Then, the wheat germination rates in different soils were determined.

For wheat growth tests, six seedlings of uniform size were transferred to a brown polypropylene bottle, which was filled with $250 \mathrm{~mL}$ of sterilized ultrapure waters containing $12.5 \mathrm{~g}$ soil. The polypropylene bottles were placed in the growth chamber, and the climate chamber was adjusted to $16 \mathrm{~h}$ of daylight, day/night temperature of $25 / 20{ }^{\circ} \mathrm{C}$. On day 21 , the wheat plants were harvested, and the root length, shoot length, wet weight and dry weight of each plant were measured.

\section{Toxicity to algae and contribution of persistent free radicals versus reactive oxygen species}

Green algae Chlorella sp. was obtained from the Institute of Oceanology, Chinese Academy of Sciences, Qingdao. Preparation of the algae cultivation medium is detailed in Text 
S5. In an Erlenmeyer, $20 \mathrm{~mL}$ of algae cultivation medium is mixed with $1 \mathrm{~g}$ of soil. After $1 \mathrm{~h}$ incubation at $37^{\circ} \mathrm{C}$, the growth rate was monitored by optical density (OD), as follows $200 \mu \mathrm{L}$ reaction mixture containing green algae was transferred into a costar 3590 ELISA plate and then analyzed with the microplate reader SpectraMax M5 at $680 \mathrm{~nm}$.

To distinguish the effects of PFRs and ROS on the inhibition of algae, we added chemical scavengers in the medium before incubation: either $10 \mathrm{mM}$ ascorbic acid (AA) to trap $\mathrm{O}_{2}{ }^{--}, \mathrm{H}_{2} \mathrm{O}_{2}$ and $\cdot \mathrm{OH}$, or $0.5 \mathrm{mg} / \mathrm{L}$ superoxide dismutase (SOD) to scavenge $\mathrm{O}_{2}{ }^{--}$, or $10 \mathrm{mM}$ catalase (CAT) to scavenge $\mathrm{H}_{2} \mathrm{O}_{2}$, or $0.5 \mathrm{mM}$ tert-butanol (TBA) to scavenge $\cdot \mathrm{OH}$ (Zhu et al. 2020) (Figure S2).

\section{Statistical analysis}

All experiments were repeated for three times, and the results were analyzed with ANOVA. The correlation analyses were conducted by SPSS 19.0 (SPSS Software, USA), with significance levels of $P<0.05$ and $P<0.01$, respectively.

\section{Results and discussion}

\section{Effect of soil heating on persistent free radicals}

We analyzed persistent free radicals (PFRs) in soils spiked with anthracene and heated $1 \mathrm{~h}$ from at $100-600{ }^{\circ} \mathrm{C}$, using electron paramagnetic resonance (EPR). Results show strong PFRs signals in heated soils, maximizing at $300{ }^{\circ} \mathrm{C}$, and almost no signal for the unheated anthracene-spiked soils (Figure S3) and heated raw soils without anthracene (Figure S1). This finding confirms that PFRs signals are induced by both heating and the presence of PAHs, as shown for benzo[a]pyrene-spiked soils heated at $100-200{ }^{\circ} \mathrm{C}$ (Liu et al. 2020). Rising the temperature was also necessary to form PFRs during adsorption of dichlorobenzene on cupric oxidecontaining particles at $100-400{ }^{\circ} \mathrm{C}$ (Lomnicki et al. 2008).

Our data show that the PFRs intensity increases from 100 to $300{ }^{\circ} \mathrm{C}$, reaching $1.88 \times 10^{17}$ spins $^{-1}$ at $300{ }^{\circ} \mathrm{C}$, and then decreases to $600{ }^{\circ} \mathrm{C}$ (Fig. 1a). The increase in PFRs from 100 to $300{ }^{\circ} \mathrm{C}$ is explained partly by the decreasing concentration of anthracene (Figure S4), which suggests the transformation of anthracene into anthracene-PFRs (Liu et al. 2020). A decline of PFRs above $300{ }^{\circ} \mathrm{C}$ may be due to radical decomposition, recombination and transformation
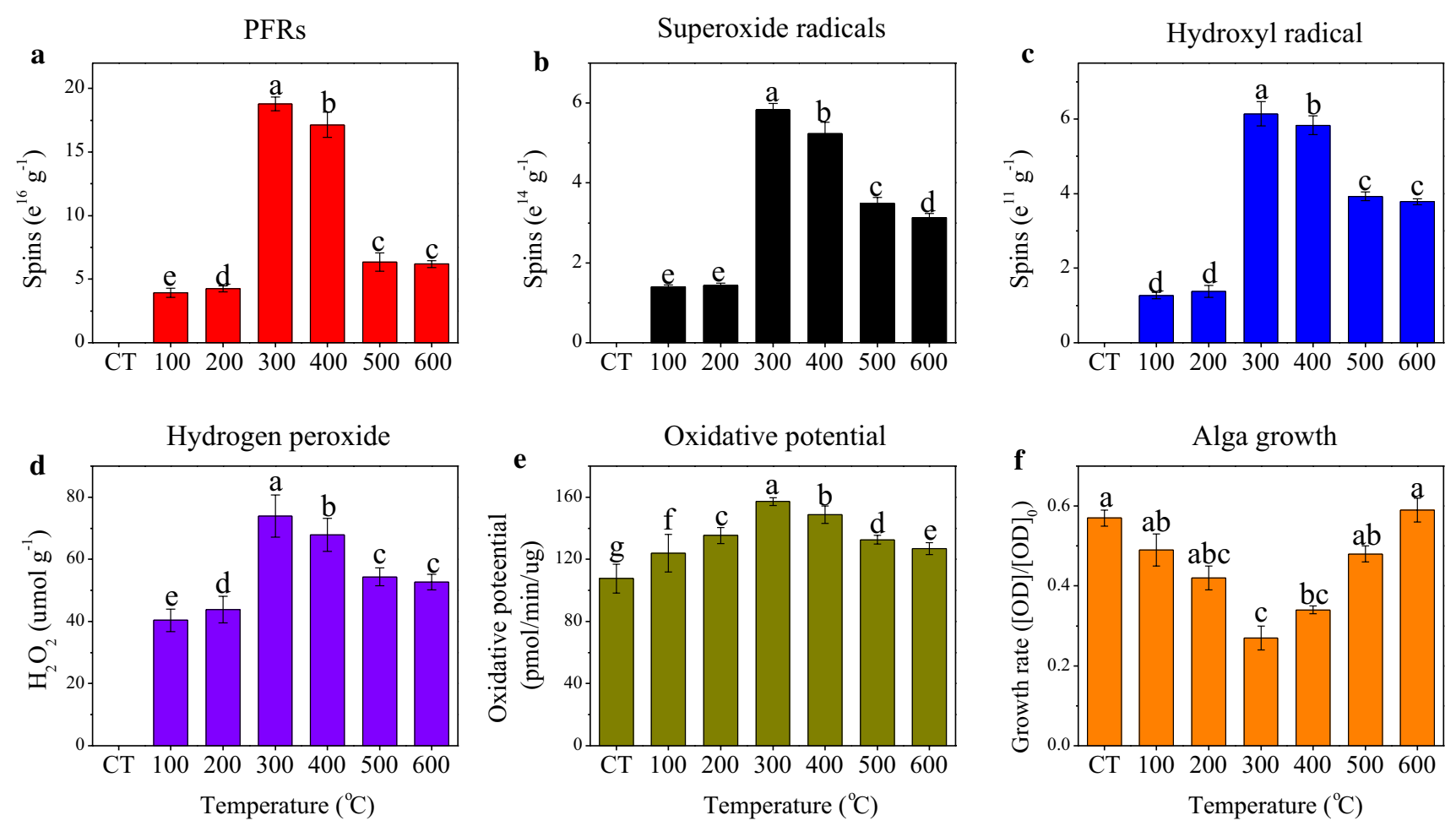

Fig. 1 Effect of soil heating on a persistent free radicals (PFRs) and reactive oxygen species (ROS), b superoxide radical $\mathrm{O}_{2}{ }^{--}, \mathbf{c}$ hydroxyl radical $\cdot \mathrm{OH}$, d hydrogen peroxide $\mathrm{H}_{2} \mathrm{O}_{2}$, e oxidative potential, and f growth of the green algae Chlorella. Error bars and letters denote

standard deviations and significant differences at $P$ below 0.05 . CT: control unheated soil with anthracene. $[\mathrm{OD}]_{0}$ and $[\mathrm{OD}]$ are the initial optical density of algae and the optical density after $1 \mathrm{~h}$ growth, respectively 
into stable compounds, similarly to what is observed in the biomass charring process (Gao et al. 2018; Odinga et al. 2019). Noteworthy, similar upward-downward trends with temperature have been observed for phenolic-contaminated soils (Zhang et al. 2019) and for coal (Chang et al. 2017). Furthermore, our results show that the formed PFRs are rather stable with less than $3 \%$ concentration decline after 44 d (Figure S5), which confirms the persistency of PAH-PFRs (Liu et al. 2020) and suggests possible long-term toxicity.

Overall, our results show that thermal treatment induces the formation of PFRs; PFRs concentration is peaking at $300{ }^{\circ} \mathrm{C}$; and PFRs display persistence over weeks, which implies potential toxicity. The next section focuses on reactive oxygen species.

\section{Effect of soil heating on reactive oxygen species}

The concentration of reactive oxygen species (ROS) is also showing a successive upward-downward trends peaking at $300{ }^{\circ} \mathrm{C}$ (Fig. 1b-d). For instance, the concentrations of $\mathrm{O}_{2}{ }^{-}$and $\cdot \mathrm{OH}$ increased with temperature, reaching $5.83 \times 10^{14}$ spins g $^{-1}$ for $\mathrm{O}_{2}^{--}$and $6.13 \times 10^{11}$ spins g $^{-1}$ for . $\mathrm{OH}$ at $300{ }^{\circ} \mathrm{C}$, then decreased. A same trend was observed for $\mathrm{H}_{2} \mathrm{O}_{2}$ extracted from thermally-treated soil suspensions. Here we hypothesize that ROS formation is linked to the formation of anthracene-PFRs. This hypothesis is strengthened by the occurrence of typical 6-line spectra of DMPO - OOH adducts and 4-line spectra of DMPO - OH adducts in heated soils, and their absence in unheated anthracene-spiked soils (Figure S6), which proves that the generation of $\mathrm{O}_{2}{ }^{-}$and $\cdot \mathrm{OH}$ is induced on the formation of PFRs. We therefore suggest the following mechanism: 1 . Electrons are transferred from anthracene-PFRs to $\mathrm{O}_{2}$, forming the superoxide radical $\mathrm{O}_{2}{ }^{--} ; 2 . \mathrm{O}_{2}{ }^{--}$dismutates with $\mathrm{H}^{+}$to form $\mathrm{H}_{2} \mathrm{O}_{2} ; 3 . \mathrm{H}_{2} \mathrm{O}_{2}$ is reduced by soil transition metals and transformed to $\mathrm{OH}$ (Khachatryan et al. 2011; Liao et al. 2014), which is supported by the high levels of metals in our soil: $21,084 \mathrm{mg} \mathrm{kg}^{-1} \mathrm{Fe}$ and $24 \mathrm{mg} \mathrm{kg}^{-1} \mathrm{Cu}$.

Overall, our results show that ROS concentrations show the same trends as PFRs in heated anthracene-spiked soils, and that ROS formation is most likely linked to PFRs formation. The next section focuses on soil oxidative potential.

\section{Effect of soil heating on soil oxidative potential}

The oxidative potential of heated anthracene-spiked soils was measured by the dithiothreitol assay to determine the effect of heating on the oxidative stress (Fig. 1e). Results show that the oxidative potential increases from 100 to $300{ }^{\circ} \mathrm{C}$ and then decreases to $600{ }^{\circ} \mathrm{C}$. This upward-downward trend is similar to trends observed for PFRs and ROS (Fig. 1a-d), thus indicating that the oxidative potential is closely linked to the generation of PFRs and ROS. This is in agreement with previous studies that show that the oxidative potential is linked to ROS, free radicals and adverse effects in acellular assays for urban aerosols (Paul et al. 2012; Chen et al. 2018). The oxidative potential is indicative of the consumption of antioxidants, e.g. dithiothreitol, by particleassociated active components, which mainly include organic compounds, PFRs and ROS (Strak et al. 2012). Oxidative stress occurs when the production of PFRs or ROS exceeds the available antioxidant capacity (Paul et al. 2012).

Moreover, the oxidative potential of heated anthracenespiked soils, ranging from 123.8 to $157.2 \mathrm{pmol} \mathrm{min}^{-1} \mu \mathrm{g}^{-1}$, are much higher than atmospheric particulate matter from biomass burning, of 4-37 pmol $\mathrm{min}^{-1} \mu \mathrm{g}^{-1}$, and coal burning, of $40 \pm 3 \mathrm{pmol} \mathrm{min}^{-1} \mu \mathrm{g}^{-1}$ (Jin et al. 2016; Fan et al. 2018). This suggests that heated anthracene-contaminated soils have much higher toxicity, e.g. upon inhalation of soil particulates. Results also show that the oxidative potential of the unheated control soils is $107.6 \pm 9.4 \mathrm{pmol} \mathrm{min}^{-1} \mu \mathrm{g}^{-1}$, which is in the same order of magnitude as an atmospheric organic aerosol (Tong et al. 2018; Chen et al. 2019).

Overall, our results showed that the oxidative potential of heated anthracene-spiked soils displays an upward-downward trend peaking at $300{ }^{\circ} \mathrm{C}$, which is similar to the trends of PFRs and ROS. In addition, the oxidative potential values of heated anthracene-spiked soils are much higher that coal and charred biomass, which suggests a notable toxicity. The next section focuses on the toxicity for plant and algae.

\section{Effect of soil heating on soil toxicity for plant and algae}

We studied the toxicity of heated anthracene-spiked soils for wheat germination and growth (Fig. 2) and for the growth of green algae (Fig. 1f). The low wheat germination rate of the unheated anthracene-spiked soil is probably due to the presence of phytotoxic compounds that may induce hypoxia, inner dehydration, impaired biochemical function, and embryo death (Tang et al. 2011). We speculate that these phytotoxic compounds are degraded upon heating at $100{ }^{\circ} \mathrm{C}$ and above. The presence of anthracene, a 3-ring PAH, is unlikely to cause toxicity at room temperature, as suggested by the absence of toxic effects of 3-5 ring PAHs on plant germination (Henner et al. 1999).

Upon heating of anthracene-spiked soils, all wheat factors such as germination, root and shoot length, and dry weight, show an overall cratering trend dropping first from 100 to $300{ }^{\circ} \mathrm{C}$, then rising to $600{ }^{\circ} \mathrm{C}$ (Fig. 2). We observe a similar cratering trend for algae (Fig. 1f). These findings mean that soil toxicity for plants and algae increase with temperature to reach a maximum at $300^{\circ} \mathrm{C}$. Moreover, the growth of algae and the growth indicators of wheat are significant negatively correlated to PFRs and ROS concentration, and to the levels of oxidative potential, with correlation coefficients ranging 

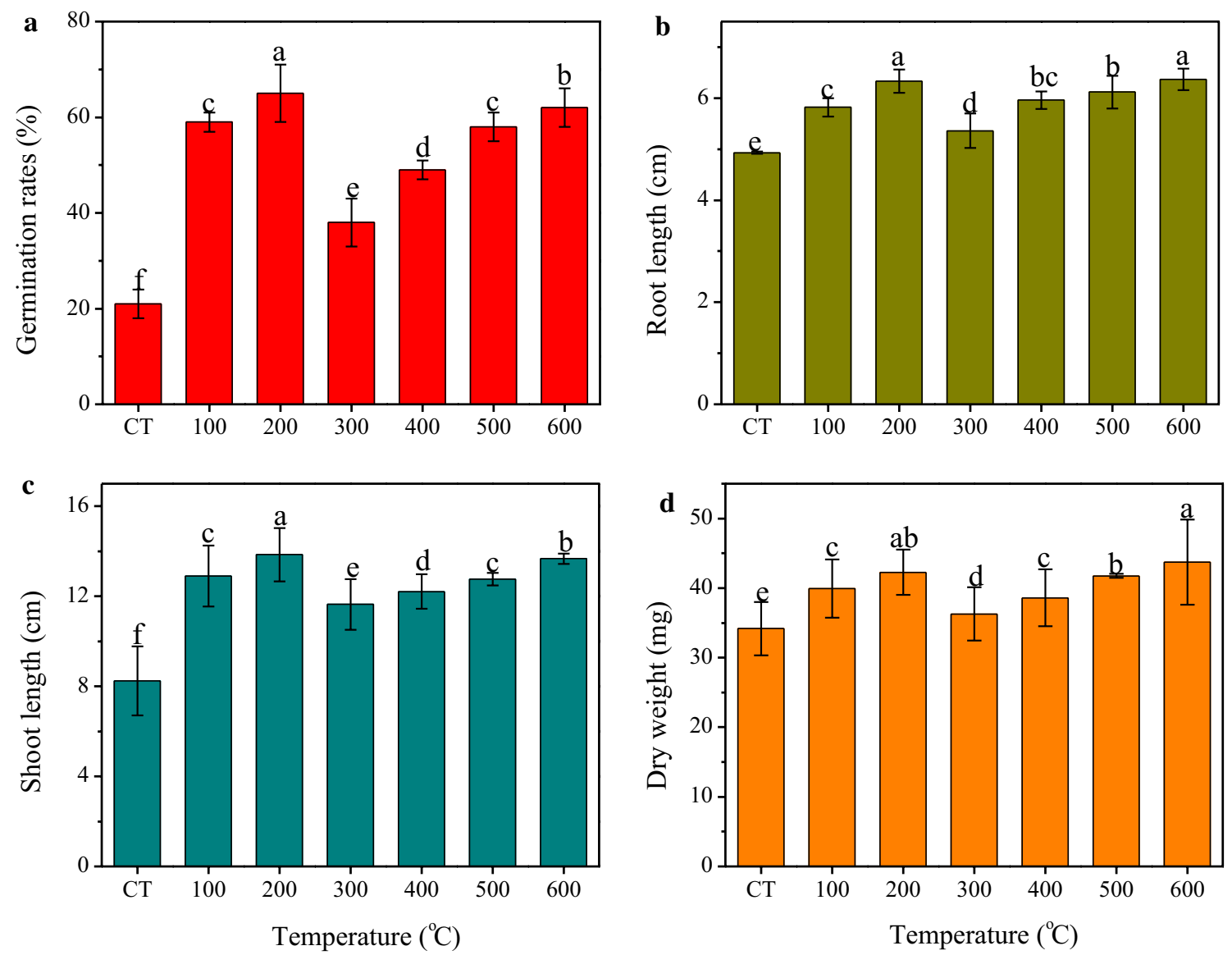

Fig. 2 Effect of soil heating on wheat a germination rate, $\mathbf{b}$ root length, $\mathbf{c}$ shoot length and $\mathbf{d}$ dry weight. Error bars and letters denote standard deviations and significant differences at $P$ below 0.05 . CT: control unheated soil with anthracene

from -0.57 to -0.93 and -0.49 to -0.93 for algae and wheat, respectively (Table S3). In other words, the highest levels of PFRs, ROS and oxidative potential induce the highest toxicity for plants and algae. Plant toxicity was previously observed in PFRs-containing biochars, which inhibited wheat germination and growth (Odinga et al. 2019; Ruan et al. 2019). In the same vein, biochar PFRs damage plasma membranes when spins intensity reach about $10^{16}$ spins $\mathrm{g}^{-1}$ (Liao et al. 2014). By comparison, our results display higher spin intensities, of $3.93-18.8 \times 10^{16}$ spins $^{-1}$, which may partly explain wheat inhibition by membrane rupture. Moreover, PFRs-containing soils have been shown to exhibit acute toxicity to luminescent bacteria (Bastos et al. 2014; Zhang et al. 2019) and particles having oxidative potential usually induce a higher cellular response (Ahmed et al. 2019; Chowdhury et al. 2019).

Overall, our findings demonstrate that plant and algal toxicity is peaking at $300{ }^{\circ} \mathrm{C}$ in anthracene-spiked soils, and that this trend is significantly correlated to the concentration of PFRs and ROS, and to the levels of oxidative potential.

\section{Toxicity mechanism}

Our results above have revealed that plant and algal toxicity are correlated to persistent free radicals (PFRs) and reactive oxygen species (ROS). In order to decipher the respective contributions of PFRs and ROS we grew algae in the presence of the anthracene-spiked soil heated at $300{ }^{\circ} \mathrm{C}$ since the concentration of PFRs and ROS was the highest and the inhibition of the growth of algae was the most significant. We added the following scavengers: either $10 \mathrm{mM}$ ascorbic acid to trap $\mathrm{O}_{2}{ }^{-{ }^{-}}, \mathrm{H}_{2} \mathrm{O}_{2}$ and $\cdot \mathrm{OH} ; 0.5 \mathrm{mg} / \mathrm{L}$ superoxide dismutase to scavenge $\mathrm{O}_{2}{ }^{--}$; or $10 \mathrm{mM}$ catalase to scavenge $\mathrm{H}_{2} \mathrm{O}_{2}$, or $0.5 \mathrm{mM}$ tert-butanol to scavenge $\cdot \mathrm{OH}$. Results show that addition of soil without scavenger induces a sharp decrease in algal growth from 1.67 to 0.27 (Fig. 3). All scavengers induce an increase in algal growth, which demonstrate the involvement of ROS to various extent in the mechanisms of toxicity.

Ascorbic acid re-establishes the maximum algal growth of 1.64 because ascorbic acid scavenges all ROS. Superoxide dismutase induces an algal growth of 0.87 , which means that. $\mathrm{OH}$ and $\mathrm{H}_{2} \mathrm{O}_{2}$ are responsible of $47.9 \%$ of the toxicity 


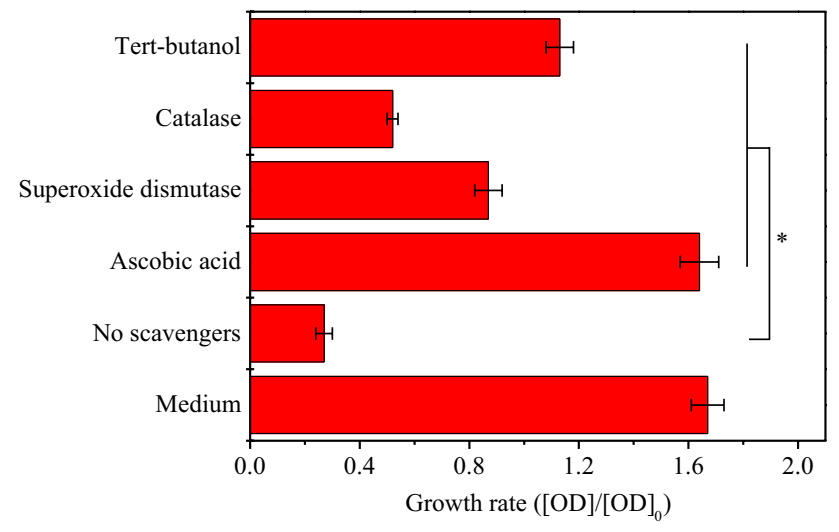

Fig. 3 Effect of scavengers on the growth rate of green algae Chlorella in $300{ }^{\circ} \mathrm{C}$ thermal-treated soil. Medium denotes without adding thermal-treated anthracene-contaminated soil. The error bars and star symbol $(*)$ in the figure represent the standard deviations and the statistically significant difference between linked data points $(P<0.05)$, respectively. $[O D]_{0}$ and $[O D]$ are the initial optical density of algae and the optical density after $1 \mathrm{~h}$ growth, respectively

versus algal growth without soil, of 1.67. The growth rate of algae decreases to 0.52 in the presence of catalase, representing $68.9 \%$ contribution of $\cdot \mathrm{OH}$ and $\mathrm{O}_{2}^{-{ }^{-}}$to the toxicity. Tert-butanol induces an algal growth of 1.13 , indicating $32.3 \%$ contribution of $\mathrm{O}_{2}{ }^{--}$and $\mathrm{H}_{2} \mathrm{O}_{2}$ to the toxicity. Contrastively, ascorbic acid induces an algal growth of 1.64, which means that anthracene-PFRs are only responsible of $1.8 \%$ of the observed toxicity, or less. This is confirmed by a complementary experiment showing that unheated soil with anthracene do not modify algal toxicity versus unheated soil alone. In other words, both anthracene and heating are necessary to induce algal toxicity. Therefore, anthracene transformation products must be indirectly involved in algal toxicity by producing ROS, on two grounds: first, there is no PFRs signal when soils are heated without anthracene, which means that $\cdot \mathrm{OH}$ and $\mathrm{O}_{2}^{--}$are not produced, and second, less than $25 \%$ of anthracene is recovered after heating at $300{ }^{\circ} \mathrm{C}$ (Figure S4), which means that $75 \%$ of anthracene is transformed by various possible mechanisms, e.g. trapping, degradation, polymerization, and reaction with other mineral or organic compounds.

Overall, our findings show that ROS induced algal toxicity with a contribution decreasing as follows: $\cdot \mathrm{OH}>\mathrm{O}_{2}{ }^{-{ }^{-}}>\mathrm{H}_{2} \mathrm{O}_{2}$. The highest contribution of $\cdot \mathrm{OH}$ to toxicity may be due to its strong oxidative potential $\mathrm{E}_{0}$ of $2.8 \mathrm{~V}$, which can cause adverse effects to organisms (Gehling et al. 2014). The direct effect of anthracene and anthracene-PFRs on algal toxicity is negligible, yet anthracene transformation products are indirectly involved in algal toxicity because they induce ROS generation.

\section{Conclusion}

This study investigated the potential risk of thermal treated anthracene-contaminated soil. Results clearly showed that PFRs with the relatively long lifetime were formed during thermal treatment of anthracene-contaminated soil, and they could induce the generation of ROS. The formed PFRs and ROS promoted the levels of oxidative potential, and posed negative effects to wheat germination and growth, algae activity. The scavengers suggested the toxicity of PFRs was mainly from the generation of ROS. Our findings indicate that thermal treatment of PAH-contaminated soil may not be so sustainable as previously assumed since PFRs may induce toxicity for living organisms. Further investigations are currently needed to quench these PFRs in thermal treatment of PAH-contaminated soil, thus ensuring the safe application of thermal treatment.

Acknowledgements This study was supported by the National Natural Science Foundation of China (Grant No. 41877126), the Shaanxi Science Fund for Distinguished Young Scholars (Grant No. 2019JC-18), the National Key R\&D Program of China (Grant No. 2018YFC1802004), the "One Hundred Talents" program of Shaanxi Province (Grant No. SXBR9171).

\section{References}

Ahmed CMS, Cui Y, Frie AL, Burr A, Bahreini R (2019) Exposure to dimethyl selenide (DMSe)-derived secondary organic aerosol alters transcriptomic profiles in human airway epithelial cells. Environ Sci Technol 53:14660-14669. https://doi.org/10.1021/ acs.est.9b04376

Banks MK, Schultz KE (2005) Comparison of plants for germination toxicity tests in petroleum-contaminated soils. Water Air Soil Poll 167:211-219. https://doi.org/10.1007/s11270-005-8553-4

Bastos AC, Prodana M, Abrantes N, Keizer JJ, Soares AMVM, Loureiro S (2014) Potential risk of biochar-amended soil to aquatic systems: an evaluation based on aquatic bioassays. Ecotoxicology 23:1784-1793. https://doi.org/10.1007/s1064 6-014-1344-1

Bryselbout C, Henner P, Carsignol J, Lichtfouse E (2000) Polycyclic aromatic hydrocarbons in highway plants and soils. Evidence for a local distillation effect. Analysis 28:290-293. https://doi. org/10.1051/analusis:2000280290

Chang T, Guo Q, Hao H, Wu B, Yang Y (2017) Formation of radicals in coal pyrolysis examined by electron spin resonance. AIP Adv 7:095303. https://doi.org/10.1063/1.4986270

Chen Q, Wang M, Sun H, Wang X, Wang Y, Li Y, Zhang L, Mu Z (2018) Enhanced health risks from exposure to environmentally persistent free radicals and the oxidative stress of PM2.5 from Asian dust storms in Erenhot, Zhangbei and Jinan. China Environ Int 121:260-268. https://doi.org/10.1016/j.envint.2018.09.012

Chen Q, Wang M, Wang Y, Zhang L, Li Y, Han Y (2019) Oxidative potential of water-soluble matter associated with chromophoric substances in PM2.5 over Xi'an. China Environ Sci Technol 53:8574-8584. https://doi.org/10.1021/acs.est.9b01976

Chen W, Chen M, Sun C, Chen T, Yan J (2020) Eggshell and plant ash addition during the thermal desorption of polycyclic aromatic 
hydrocarbon-contaminated coke soil for improved removal efficiency and soil quality. Environ Sci Pollut R 27:11050-11065. https://doi.org/10.1007/s11356-019-07531-7

Chowdhury PH, He Q, Carmieli R, Li C, Pardo M (2019) Connecting the oxidative potential of secondary organic aerosols with reactive oxygen species in exposed lung cells. Environ Sci Technol 53:13949-13958. https://doi.org/10.1021/acs.est.9b04449

Crépineau C, Rychen G, Feidt C, Le Roux Y, Lichtfouse E, Laurent F (2003) Contamination of pastures by polycyclic aromatic hydrocarbons (PAHs) in the vicinity of a highway. J Agric Food Chem 51:4841-4845. https://doi.org/10.1021/jf0210371

Dellinger B, Pryor WA, Cueto R, Squadrito GL, Hegde V, Deutsch WA (2001) Role of free radicals in the toxicity of airborne fine particulate matter. Chem Res Toxicol 14:1371-1377. https://doi. org/10.1021/tx010050x

Eriksson M, Dalhammar G, Borgkarlson A (2000) Biological degradation of selected hydrocarbons in an old PAH/creosote contaminated soil from a gas work site. Appl Microbiol Biot 53:619-626. https://doi.org/10.1007/s002530051667

Falciglia PP, Giustra MG, Vagliasindi FGA (2011) Low-temperature thermal desorption of diesel polluted soil: Influence of temperature and soil texture on contaminant removal kinetics. J Hazard Mater 185:392-400. https://doi.org/10.1016/j.jhazm at.2010.09.046

Fan X, Li M, Cao T, Cheng C, Li F, Xie Y, Wei S, Song J, Peng P (2018) Optical properties and oxidative potential of water- and alkaline-soluble brown carbon in smoke particles emitted from laboratory simulated biomass burning. Atmos Environ 194:48-57. https://doi.org/10.1016/j.atmosenv.2018.09.025

Gehling W, Khachatryan L, Dellinger B (2014) Hydroxyl radical generation from environmentally persistent free radicals (EPFRs) in PM2.5. Environ Sci Technol 48:4266-4272. https://doi. org/10.1021/es401770y

Gao P, Yao D, Qian Y, Zhong S, Zhang L, Xue G, Jia H (2018) Factors controlling the formation of persistent free radicals in hydrochar during hydrothermal conversion of rice straw. Environ Chem Lett 16:1463-1468. https://doi.org/10.1007/s10311-018-0757-0

Grova N, Laurent C, Feidt C, Rychen G, Laurent F, Lichtfouse E (2000) Gas chromatography-mass spectrometry study of polycyclic aromatic hydrocarbons in grass and milk from urban and rural farms. Eur J Mass Spectrom. https://doi.org/10.1255/ejms.371

Haritash AK, Kaushik CP (2009) Biodegradation aspects of polycyclic aromatic hydrocarbons (PAHs): a review. J Hazard Mater 169:115. https://doi.org/10.1016/j.jhazmat.2009.03.137

Henner P, Schiavon M, Morel JL, Lichtfouse E (1997) Polycyclic aromatic hydrocarbon $(\mathrm{PAH})$ occurrence and remediation methods. Analysis 25:56-59

Henner P, Schiavon M, Druelle V, Lichtfouse E (1999) Phytotoxicity of ancient gaswork soils. Effect of polycyclic aromatic hydrocarbons (PAHs) on plant germination. Org Geochem 30:963-969. https:// doi.org/10.1016/S0146-6380(99)00080-7

Inckot RC, Santos GDO, Souza LAD, Bona C (2011) Germination and development of Mimosa pilulifera in petroleum-contaminated soil and bioremediated soil. Flora 206:261-266. https://doi. org/10.1016/j.flora.2010.09.005

Jin W, Su S, Wang B, Zhu X, Tao S (2016) Properties and cellular effects of particulate matter from direct emissions and ambient sources. J Environ Sci Heal A 51:1-9. https://doi. org/10.1080/10934529.2016.1198632

Jia H, Gu C, Boyd SA, Teppen BJ, Johnston CT (2011) Comparison of reactivity of nanoscaled zero-valent iron formed on clay surfaces. Soil Sci Soc Am J 75:357-364. https://doi.org/10.2136/ sssaj2010.0080nps

Jia H, Nulaji G, Gao H, Wang F, Zhu Y, Wang C (2016) Formation and stabilization of environmentally persistent free radicals induced by the interaction of anthracene with $\mathrm{Fe}(\mathrm{III})$-modified clays. Environ
Sci Technol 50:6310-6319. https://doi.org/10.1021/acs.est.6b005 27

Jia H, Zhao S, Shi Y, Zhu L, Wang C, Sharma VK (2018) Transformation of polycyclic aromatic hydrocarbons and formation of environmentally persistent free radicals on modified montmorillonite: the role of surface metal ions and polycyclic aromatic hydrocarbon molecular properties. Environ Sci Technol 52:5725-5733. https://doi.org/10.1021/acs.est.8b00425

Jia H, Liu J, Zhu K, Gao P, Lichtfouse E (2020) High contribution of hydrocarbon transformation during the removal of polycyclic aromatic hydrocarbons from soils, humin and clay by thermal treatment at $100-200{ }^{\circ} \mathrm{C}$. Environ Chem Lett 18:923-930. https ://doi.org/10.1007/s10311-020-00972-4

Kanaly RA, Harayama S (2000) Biodegradation of high-molecular-weight polycyclic aromatic hydrocarbons by bacteria. J Bacteriol 182:2059-2067. https://doi.org/10.1128/ JB.182.8.2059-2067.2000

Kronimus A, Schwarzbauer J, Ricking M (2006) Analysis of nonextractable DDT-related compounds in riverine sediments of the Teltow Canal, Berlin, by pyrolysis and thermochemolysis. Environ Sci Technol 40:5882-5890. https://doi.org/10.1021/es0605568

Khachatryan L, Mcferrin CA, Hall RW, Dellinger B (2014) Environmentally persistent free radicals (EPFRs). 3. Free versus bound hydroxyl radicals in EPFR aqueous solutions. Environ Sci Technol 48:9220-9226. https://doi.org/10.1021/es501158r

Khachatryan L, Vejerano E, Lomnicki S, Dellinger B (2011) Environmentally persistent free radicals (EPFRs). 1. Generation of reactive oxygen species in aqueous solutions. Environ Sci Technol 45:8559-8566. https://doi.org/10.1021/es201309c

Kuppusamy S, Thavamani P, Venkateswarlu K (2016) Remediation approaches for polycyclic aromatic hydrocarbons (PAHs) contaminated soils: technological constraints, emerging trends and future directions. Chemosphere 168:944-968. https://doi.org/10.1016/j. chemosphere.2016.10.115

Laurent C, Feidt C, Grova N, Mpassi D, Lichtfouse E, Laurent F, Rychen G (2002) Portal absorption of $14 \mathrm{C}$ after ingestion of spiked milk with 14C-phenanthrene, 14C-benzo[a]pyrene or 14C-TCDD in growing pigs. Chemosphere 48:843-848. https:// doi.org/10.1016/S0045-6535(02)00145-5

Laurent C, Feidt C, Lichtfouse E, Grova N, Laurent F, Rychen G (2001) Milk-blood transfer of 14C-tagged polycyclic aromatic hydrocarbons (PAHs) in pigs. J Agric Food Chem 49:2493-2496. https:// doi.org/10.1021/jf0014011

Liao S, Pan B, Li H, Zhang D, Xing B (2014) Detecting free radicals in biochars and determining their ability to inhibit the germination and growth of corn, wheat and rice seedlings. Environ Sci Technol 48:8581-8587. https://doi.org/10.1021/es404250a

Lichtfouse E, Budzinski H, Garrigues P, Eglinton TI (1997) Ancient polycyclic aromatic hydrocarbons in modern soils: $13 \mathrm{C}, 14 \mathrm{C}$ and biomarker evidence. Org Geochem 26:353-359. https://doi. org/10.1016/S0146-6380(97)00009-0

Lichtfouse E, Wehrung P, Albrecht P (1998) Plant wax n-alkanes trapped in soil humin by noncovalent bonds. Naturwissenschaften 85:449-452. https://doi.org/10.1007/s001140050529

Liu J, Jia H, Zhu K, Zhao S, Lichtfouse E (2020) Formation of environmentally persistent free radicals and reactive oxygen species during the thermal treatment of soils contaminated by polycyclic aromatic hydrocarbons. Environ Chem Lett 18:1329-1336. https ://doi.org/10.1007/s10311-020-00991-1

Lomnicki S, Truong H, Vejerano E, Dellinger B (2008) Copper oxidebased model of persistent free radical formation on combustionderived particulate matter. Environ Sci Technol 42:4982-4988. https://doi.org/10.1021/es071708h

Merino J, Bucala V (2007) Effect of temperature on the release of hexadecane from soil by thermal treatment. J Hazard Mater 143:455461. https://doi.org/10.1016/j.jhazmat.2006.09.050 
Odinga ES, Waigi MG, Gudda FO, Wang J, Gao Y (2019) Occurrence, formation, environmental fate and risks of environmentally persistent free radicals in biochars. Environ Int 134:105172.1105172.19. https://doi.org/10.1016/j.envint.2019.105172

Paul A, Solomon M, Costantini T, J., Grahame, Miriam, E. (2012) Air pollution and health: bridging the gap from sources to health outcomes: conference summary. Air Qual Atmos Health 5:9-62. https://doi.org/10.1007/s11869-011-0161-4

Peng N, Huang C, Su J (2018) An experimental and kinetic study of thermal decomposition of phenanthrene. J Hazard Mater 365:565571. https://doi.org/10.1016/j.jhazmat.2018.11.026

Pourfadakari S, Ahmadi M, Jaafarzadeh N, Takdastan A, Neisi A, Ghafari S, Jorfi S (2019) Remediation of PAHs contaminated soil using a sequence of soil washing with biosurfactant produced by Pseudomonas aeruginosa strain PF2 and electrokinetic oxidation of desorbed solution, effect of electrode modification with $\mathrm{Fe}_{3} \mathrm{O}_{4}$ nanoparticles. J Hazard Mater 379:120839.1-120839.14. https:// doi.org/10.1016/j.jhazmat.2019.120839

Ruan X, Sun Y, Du W, Tang Y, Liu Q, Zhang Z, Doherty W, Frost RL, Qian G, Tsang DCW (2019) Formation, characteristics, and applications of environmentally persistent free radicals in biochars: a review. Bioresour Technol 281:457-468. https://doi.org/10.1016/j. biortech.2019.02.105

Strak M, Janssen NAH, Godri KJ, Gosens I, Mudway IS, Cassee FR, Lebret E, Kelly FJ, Harrison RM, Brunekreef B (2012) Respiratory health effects of airborne particulate matter: the role of particle size, composition, and oxidative potential-the RAPTES project. Environ Health Perspect 120:1183-1189. https://doi. org/10.1289/ehp.1104389

Tang J, Wang M, Wang F, Sun Q, Zhou Q (2011) Eco-toxicity of petroleum hydrocarbon contaminated soil. J Environ Sci 23:845-851. https://doi.org/10.1016/S1001-0742(10)60517-7

Tong H, Lakey PSJ, Arangio AM, Socorro J, Shen F, Lucas K, Brune WH, Pöschl U, Shiraiwa M (2018) Reactive oxygen species formed by secondary organic aerosols in water and surrogate lung fluid. Environ Sci Technol 52:11642-11651. https://doi. org/10.1021/acs.est.8b03695

Wang Y, Zhang C, Lin M, Ge Y (2016) A symbiotic bacterium differentially influences arsenate absorption and transformation in Dunaliella salina under different phosphate regimes. J Hazard Mater 318:443-451. https://doi.org/10.1016/j.jhazm at.2016.07.031

Zhang L, Cao Y, Colella NS, Liang Y, Bredas JL, Houk KN, Briseno AL (2015) Unconventional, chemically stable, and soluble twodimensional angular polycyclic aromatic hydrocarbons: from molecular design to device applications. Acc Chem Res 48:500509. https://doi.org/10.1021/ar500278w

Zhang Y, Guo X, Si X, Yang R, Quan X (2019) Environmentally persistent free radical generation on contaminated soil and their potential biotoxicity to luminous bacteria. Sci Total Environ 687:348-354. https://doi.org/10.1016/j.scitotenv.2019.06.137

Zhao S, Zhang C, Ni Z, Zhu K, Liu J, Dai Y, Jia H (2020) Optimized extraction of environmentally persistent free radicals from clays contaminated by polycyclic aromatic hydrocarbons. Environ Chem Lett 18:949-955. https://doi.org/10.1007/s10311-02000982-2

Zhu K, Jia H, Zhao S, Xia T, Guo X, Wang T, Zhu L (2019) Formation of environmentally persistent free radicals on microplastics under light irradiation. Environ Sci Technol 53:8177-8186. https://doi. org/10.1021/acs.est.9b01474

Zhu K, Jia H, Sun Y, Dai Y, Zhang C, Guo X, Wang T, Zhu L (2020) Long-term phototransformation of microplastics under simulated sunlight irradiation in aquatic environments: roles of reactive oxygen species. Water Res. https://doi.org/10.1016/j.watre s.2020.115564 